\begin{tabular}{|c|c|c|c|c|c|c|c|}
\hline Drug/Pathology & $\begin{array}{l}\text { No. of patients } \\
\text { treated }\end{array}$ & $\begin{array}{l}\text { No. different } \\
\text { dosages }\end{array}$ & $\begin{array}{l}\text { Syringes } \\
\text { made }\end{array}$ & $\begin{array}{l}\text { Syringes } \\
\text { consumed }\end{array}$ & $\begin{array}{l}\text { Cost of full } \\
\text { dosage form }\end{array}$ & $\begin{array}{l}\text { Cost of } \\
\text { individualization }\end{array}$ & Saving \\
\hline Adalimumab/Rheumatoid Arthritis & 3 & 2 & 70 & 35 & $€ 33,971.00$ & $€ 17,519.31$ & $€ 16,451.69$ \\
\hline Anakinra/Juvenile Idiopathic Arthritis & 6 & 9 & 2274 & 809 & $€ 58,680.57$ & $€ 34,804.94$ & $€ 23,875.63$ \\
\hline Pegfilgrastim/Congenital Neutropenia & 1 & 1 & 148 & 74 & $€ 92,352.00$ & $€ 4,7263.84$ & $€ 45,088.16$ \\
\hline
\end{tabular}

The results are expressed in the above table:

Conclusions Individualization of dosage represents both an optimization of resources and increased patient safety. Repackaging improves difficult-to-measure volume management, avoiding handling in unsuitable conditions by the patient.

No conflict of interest.

\section{OHP-060 PAEDIATRIC CLINICAL RESEARCH: CURRENT SITUATION AND PHARMACEUTICAL CONSTRAINTS IN FRANCE AND CANADA}

doi:10.1136/ejhpharm-2013-000276.434

${ }^{1} \mathrm{~A}$ Guérin, ${ }^{1} \mathrm{C}$ Tanguay, ${ }^{1} \mathrm{D}$ Lebel, ${ }^{2} \mathrm{~S}$ Prot-Labarthe, ${ }^{2} \mathrm{O}$ Bourdon, ${ }^{1} \mathrm{JF}$ Bussières. ${ }^{1} \mathrm{CHU}$ Sainte-Justine, Pharmacy, Montreal, Canada; ${ }^{2}$ Hôpital Universitaire Robert-Debré, Pharmacy, Paris, France

Background Paediatric clinical research represents a challenge and faces particular pharmaceutical constraints.

Purpose The main objective was to describe the current pharmaceutical situation in paediatric clinical research in France and Canada. The secondary objective was to identify factors that discourage paediatric clinical research.

Materials and Methods Cross-sectional survey of 12 pharmacy departments from France and 12 from Canada with an online 50-question survey (June-September 2012). The median [minimummaximum] was calculated for each country and compared using the Mann-Whitney or Fisher's exact test. Respondents were asked to rank, in order of importance from 1-10 (1 being the most important), factors that discourage paediatric clinical research.

Results There was a similar number of ongoing paediatric clinical trials in France and Canada (38 [10-81] vs. 20 [4-178], p = 0.205). A lower number of pharmacists per hospital was observed in France (17 [11.5-35] vs. 45 [18.9-76.8], $p=0.009)$, but a similar number of pharmacists were assigned to clinical trials (1.5 [1-3] vs. 1.9 [0.2-17.4], $p=0.921)$. Institutional protocols represented the majority of paediatric clinical trials in France (61\% [14-100] vs. 25\% [0-100]). Similar services were offered, but the majority of French respondents offered help with institutional protocol development ( $91 \%$ vs. $50 \%, p=0.063$ ). The majority of respondents reported that the payment provided by the investigators was insufficient to cover pharmaceutical support costs and that formulations were not easily obtained from manufacturers. Respondents from both countries ranked more highly the same factors that discourage paediatric clinical research, such as absence of financial interest from the pharmaceutical industry (median rank 2 [1-6] vs. 4 [1-10]), prohibitive cost versus profit ratio (2 [1-3] vs. 3 [2-9]), small patient cohorts per hospital (2 [1-7] vs. 4.5 [1-10] and the non-availability of appropriate drug formulations (3 [1-9] vs. 5 [1-10]).

Conclusions Similar constraints were identified in France and Canada. Further studies are required to identify relevant incentives to better support pharmacists' role in paediatric clinical research.

No conflict of interest.

\section{OHP-061 PARENTERAL NUTRITION: STANDARIZED PROCESS FROM PRESCRIPTION TO PREPARATION}

doi:10.1136/ejhpharm-2013-000276.435

L Casorati, A Ragazzi, VM Conte, M Savoldelli, MG Ottoboni, D Ferla, TE Testa. "Ospedale Maggiore" di Crema, Pharmacy, Crema, Italy
Background It is widely recognised that Total Parenteral Nutrition (TPN) is essential for the patient's survival and not just for simple assistance. Therefore, it's important that sufficient attention is devoted to assessing the patient's nutritional status. The department of Pharmacy has always been involved in the management of TPN to support the clinical and therapeutic needs of the patient.

Purpose To facilitate the physician's delicate task of prescribing a balanced nutritional formula, identifying some standard formulas/ recipes for parenteral nutrition bags.

Materials and Methods These standard prescriptions have been developed with a nutritionist and the Surgery team and they cover both peripherally administered (low osmolarity) and centrally administered (high osmolarity) solutions. Depending on the patient's clinical needs, we have standardised prescriptions with different volumes (2000 or $2500 \mathrm{ml}$ ). In addition to the patient's personal data and anthropometric information, these prescriptions already include all the necessary elements for a balanced diet, including calorie requirements, key macronutrients, proteins, water and micronutrients.

Results This review has provided standardised guidance and support to the medical staff in writing the prescriptions for TPN, also giving a range of choices in the initial nutritional approach to the patients. Standardized prescriptions offer a better balance of electrolyte content than those of ready-to use commercial formulations. This approach has improved familiarity with TPN throughout the hospital, by implementing the use of customised bags not only in critical care departments, leading to better cost management.

Conclusions The purpose of nutritional support is not only to avoid malnutrition and its complications, but also to change the pathogenic mechanisms of diseases. For a proper use of artificial nutrition it is necessary to have an in-depth knowledge of the problems of malnutrition. For this reason, it is essential to have a multi-disciplinary approach in which the pharmacist connects different functions.

No conflict of interest.

\section{OHP-062 PATIENT-ORIENTED CARE IN PHARMACY CONSULTATION CENTRE: ANALYSIS OF PHARMACIST INTERVENTIONS}

doi:10.1136/ejhpharm-2013-000276.436

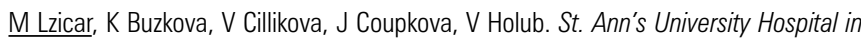
Brno, Hospital Pharmacy, Brno, Czech Republic

Background The number of drugs used has increased in recent years. Some patients need an explanation of how to use their drugs and how to prevent medical errors. The pharmacy consultation centre in St. Ann University Hospital has offered a service for more than 11 years for in- and outpatients. They can consult pharmacists about their drug-related problems.

Purpose To analyse what the most frequent topics of consultations were in 2011 and 2012.

To find out how pharmacists provide counselling to patients by repeat cheque-up appointments.

Materials and Methods Patient records were examined retrospectively in 2011 and 2012 (January-September) looking at the number of visits, age and sex of patients, topics of patient questions. Pharmacists offered patients repeat cheque-up appointments to increase the compliance with recommendations.

Results The authors performed 85 consultations in the last two years for 47 patients (number of new patients: 25 in 2011, 22 in 2012). Median age was 64.5 years, 25 women and 22 men. Median 